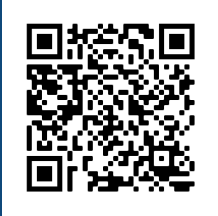

Keywords:

Carotenoids Effect size

Fluorescence

Physiology

Pollution

Historic:

Received 06/01/2020

Accepted 22/05/2020

+Correspondence: antoniorodrigues.biologia@gmail.com
Antonio Rodrigues da Cunha Netolat, Alexandra dos Santos Ambrósio ${ }^{2 a}$, Marina Wolowski ${ }^{2 b}$, Tainara Bettiol Westin ${ }^{2 c}$, Kamilla Pacheco Govêa ${ }^{2 \mathrm{~d}}$, Marilia Carvalho ${ }^{2 e}$, Sandro Barbosa ${ }^{2 f}$

\section{NEGATIVE EFFECTS ON PHOTOSYNTHESIS AND CHLOROPLAST PIGMENTS EXPOSED TO LEAD AND ALUMINUM: A META-ANALYSIS}

CUNHA NETO, A. R.; AMBRÓSIO, A. S.; WOLOWSKI, M.; WESTIN, T. B.; GOVÊA, K. P.; CARVALHO, M.; BARBOSA, S. Negative effects on photosynthesis and chloroplast pigments exposed to lead and aluminum: a meta-analysis. CERNE, v. 26, n. 2, p.232-237, 2020.

\section{HIGHLIGHTS}

In general, toxic metals cause negative effects on plants' physiology.

Lead reduces chlorophyll B, negatively impacting photosynthesis and the photosystem II.

Aluminum acts negatively specially in chloroplast pigments.

Fabaceae family do not present changes in physiology when exposed to those Toxic Metals.

\section{ABSTRACT}

Toxic metals have become some of the main abiotic agents that influence the stress of organisms due to their numerous agricultural and industrial uses that result in bioaccumulation and toxicity at different levels, depending on the type and concentration in the environment. Aluminum and lead are present as a result of anthropogenic activities and cause soil contamination and, consequently, pollution effects on producers such as plants. In this review, we used meta-analysis techniques to assess the effect of aluminum and lead on plant physiology. We calculated the overall effect size for the response variables photosynthesis, maximum quantum efficiency of photosystem II and plastid pigments (chlorophyll a, chlorophyll b and carotenoids). Moreover, it was possible to test the the effect of each metal and the phylogenetic relationship for the probability of Fabaceae species to respond to the pollution caused by these heavy metals, due to the number of studies found using this family. Overall, exposure to the toxic metals at high magnitudes affects photosynthesis and chlorophyll $b$ (by reducing its amount). When considering the effect of each metal separately, aluminum reduced the content of the chlorophyll a and chlorophyll b. However, lead reduced photosynthesis, maximum quantum efficiency of photosystem II and chlorophyll b. When considering the Fabaceae species, there was no reduction of the parameters analyzed under stress by toxic metals. Therefore, our results confirm that these toxic metals (aluminum and lead) are toxic to plant physiology, mainly affecting the efficiency of the photosynthetic system and the plastid content. 


\section{INTRODUCTION}

Toxic metals are classified as chemical elements with a density greater than $5 \mathrm{~g} \cdot \mathrm{cm}^{-3}$ or an atomic number greater than 20 (using calcium as a reference), are associated with pollution problems but occur naturally on Earth, and are released during the process of erosion, volcanism and some other naturally occurring disasters (Ozyigit et al., 2016). Industrial and mining activities commonly increase the release of toxic metals through their effluents, which also contain chemicals and other pollutants. These chemicals and pollutants are usually treated and their final destination (e.g., landfills and places that treat waste and effluent) is decided by environmental managers (Li et al., 20I8). However, untreated effluent is sometimes released, harming ecosystems, biodiversity and human health. The destruction of vegetation cover and the degradation of soil are consequences of the leaching of these metals, which is the main route of contamination of water sources, rivers and groundwater (Tozsér et al., 2017).

As a result of industrial and agricultural expansion, toxic metals have become some of the main abiotic agents that influence the stress of organisms and their bioaccumulation and toxicity are found at different environmental levels. Even at low concentrations, toxic metals such as arsenic, cadmium, chromium, mercury, lead and aluminum are potentially toxic to organisms (Ozyigit et al., 2016). However, there are metals (e.g., copper, iron, manganese, molybdenum, nickel and zinc) that are essential for several biological processes but are harmful at high concentrations (Ozyigit et al., 2016).

Plants sensitive to toxic metal contamination, such as the Myrica genus, exhibit toxicity symptoms, indicating the presence of these elements in the environment. The plasma membrane can be affected by toxic metals, since it is the first to establish a relationship with these contaminants (He et al., 20l8). Photosynthesis of plants exposed to toxic metal contamination is also compromised, since these elements can reduce the levels of chlorophyll and carotenoids due to the inactivation of the enzymes responsible for the biosynthesis of these pigments. Harmful effects on the electron transport chain, inactivation of the Calvin cycle enzymes and reduction of stomatal conductance have also been reported (Marques et al., 2018).

Lead $(\mathrm{Pb})$ is a major pollutant because it is a potentially toxic metal and accumulates for many years in the soil. It damages the development and negatively affects the physiological and biochemical structures of plants, inhibiting photosynthesis, altering enzymatic activities, and causing the inhibition or reduction of germination and chlorosis in the leaves (Ozyigit et al., 2016). Therefore, $\mathrm{Pb}$ has the potential to modify anatomical characteristics, such as the number of stomas, stomatal conductance and the size of vascular bundles (He et al., 2018). Moreover, $\mathrm{Pb}$ can cause oxidation of the root system and change the water and hormonal balance. Another important plant response to toxic metal exposure is foliar gas exchange because it reflects different levels of environmental stress and can be directly related to photosynthesis (He et al., 2018). According to Fu and Wang (2015), when Brassica chinensis was exposed to small amounts of $\mathrm{Pb}(300 \mathrm{mg} /$ $\mathrm{Kg}$ ) the metal promoted an increase in photosynthetic capacity and carbon assimilation. However, a decline and inhibition of these two responses were reported at a concentration of $900 \mathrm{mg} / \mathrm{Kg}$ of $\mathrm{Pb}$. Moreover, at lower concentrations, $\mathrm{Pb}$ does not alter the production of plastid pigments, maintaining the photosynthetic rate (Fu and Wang, 20I5; Ozyigit et al., 2016). However, at high concentrations (i.e., $100 \mu \mathrm{mol}$ to $400 \mu \mathrm{mol}$ ) Pb tends to inhibit the production of chlorophyll $a$ and $b$ and carotenoids (Ozyigit et al., 2016).

Aluminum (Al) contamination releases nitrate and hydrogen, causing the $\mathrm{pH}$ to decrease. At low $\mathrm{pH}$, hydrogen $\left(\mathrm{H}^{+}\right)$acts on minerals by releasing aluminum ions $\left(\mathrm{Al}_{3}^{+}\right)$that are predominantly retained by the negative charges of soil clay particles, in equilibrium with $\mathrm{Al}_{3}{ }^{+}$in solution. Thus, the amount of $\mathrm{Al}_{3}{ }^{+}$in solution increases with soil acidity. Consequently, this leads to a reduction in the availability of nutrients and $\mathrm{Al}$ accumulation in different parts of the plant, affecting cells and organelles at the cytogenetic, morphological and physiological levels. This affects plant development mainly in the root, which exhibits the first visible sign of toxicity (Matsumoto and Motoda, 2013; Zhang et al., 2018). However, Al can positively contribute to plant physiology and growth when used in hydroponic cultivation because this technique associates Al with the composition of nutrients supplied to plants, providing better phytosanitary control (Quian et al., 2018). Aluminum is preferentially bound to the cell wall components and has high affinity for carboxyl and phosphate groups, as well as a preference for oxygen donors (Zhang et al., 2018). Together with low $\mathrm{pH}, \mathrm{Al}$ affects nutrient accumulation, leading to nutritional deficiencies in many species (Quian et al., 2018). Al toxicity also causes lesions in cell structures, such as the nucleus, cytoskeleton, plasma membrane and cell wall; consequently, this impairs cell division and expansion, resulting in restricted growth and unhealthy foliage (Mendes et al., 20I8). 
Photosynthesis is another process sensitive to environmental stress from excess Al. This leads to a decrease in the content of plastid pigments, causing signaling mechanisms that initiate appropriate changes to the photosynthetic apparatus at physiological and biochemical levels in response to environmental changes (Matsumoto and Motoda, 20I3). In this context, Al also reduces the capacity of electron transport and, consequently, the assimilation of internal carbon, which is possibly associated with thylakoid damage (Zhang et al., 20I8).

Considering the data available in the literature and the variation of physiological responses of plants to exposure to toxic metals, the aim of this review was to identify, through the technique of meta-analysis, general patterns related to the effects of toxic metals (lead and aluminum) on plant photosynthesis.

\section{MATERIAL AND METHODS}

We reviewed the studies through a systematic literature search, of the "Web of Science" and "Periódicos Capes" databases, using the following topics as keywords: "toxic metal" and "lead and photosynthesis," "aluminum and photosynthesis," "lead and chloroplast pigments" and "aluminum and chloroplast pigments,"; in addition, we also selected dissertations and theses (complementary material I).

We selected studies that reported values of average and standard deviation of the following response variables: photosynthesis, efficiency of photosystem II (Fv/ $\mathrm{Fm}$ ), chlorophyll a, chlorophyll b and carotenoids under different experimental concentrations of $\mathrm{Pb}$ and $\mathrm{Al}$. We excluded articles that did not study $\mathrm{Pb}$ and $\mathrm{Al}$ and those that did not include the standard deviation. The data were recorded, including the family of each species studied.

The effect size was calculated for each studied case as the standardized mean difference (d) obtained from the equation, where $X I$ is the mean of the control, $X 2$ is the average of the treatment and Swithin is the standard deviation parameter that considers the standard deviation and the sample size both of the control and the treatment.

$d=\frac{X 1-\mathrm{X} 2}{\text { Swithin }}$

The variance $(V d)$ of $d$ was calculated as, Where $n \mathrm{I}$ is the error of the control, $\mathrm{n} 2$ is the error of the treatment.

$$
V d=\frac{n 1+n 2}{n 1 n 2}+\frac{d^{2}}{2(n 1+n 2)}
$$

The negative value of $\mathrm{d}$ means that $\mathrm{Al}$ or $\mathrm{Pb}$ promoted an increase in the activity of the parameter analyzed in relation to the control and positive values mean that the metal analyzed reduced the activity in relation to the control.
The overall effect size was calculated using random effects models for each response variable. These models were used because they attribute the effect size distribution to the actual differences among the cases and do not assume that the sampling error is the only source of differences among them. A Z test was performed with a $95 \%$ confidence interval and the maximum and minimum values were calculated to determine if the effect size differed from a normal distribution (Tozsér et al., 2017; Gurevitch et al., 2018). Moreover, the heterogeneity was assessed in order to identify moderators that would explain potential differences among the cases. Model assumptions and the publication bias were verified using a variety of methods (normal $\mathrm{QQ}$, influence graph, funnel graph, symmetry test and fail-safe number) and the metafor package in the $R$ environment ( $R$ Development Core Team 2012).

\section{RESULTS}

A total of 124 scientific articles published from 2005 to 2016 were reviewed which 166 case studies were extracted using the inclusion and exclusion criteria (complementary material I). The overall effect size indicated that the metals acted negatively on photosynthesis (4.25) and chlorophyll b (0.7I), while for the response variables $\mathrm{Fv} / \mathrm{Fm}$, chlorophyll a and carotenoids, the metals did not show an effect on plant physiology.

When analyzing the effect by each toxic metal (Figure I), Pb negatively affected photosynthesis (25.16), Fv/ Fm (I.76) and chlorophyll b (2.52), while chlorophyll a and carotenoids were not significant for $\mathrm{Pb}$. However, Al had a negative effect on chlorophyll a (8.65) and b (6.45) (Figure I). The other response variables had less than 10 cases, making it not possible to consider $\mathrm{Al}$ as a moderator in the analysis.

Considering the plant families as moderators, only Fabaceae (Figure 2) presented enough case numbers to be analyzed. The response variables related to the plastid pigments and Fv/Fm did not have significant values, indicating that the metals did not interfere with the production of these pigments and in the reaction centers of photosystem II by the Fabaceae species.

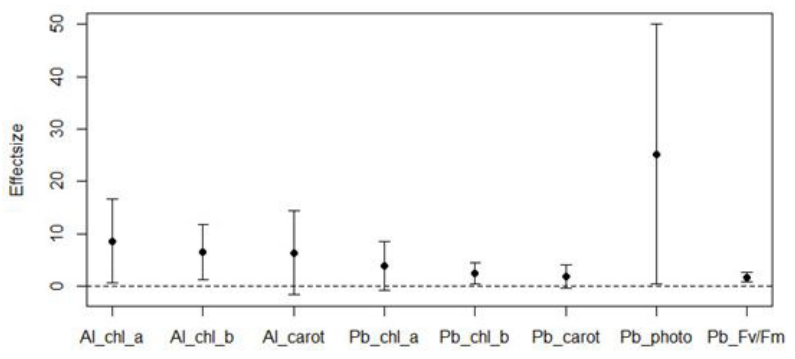

FIGURE I Effect size of aluminum and lead on chlorophyll a, chlorophyll b, carotenoids, photosynthesis and Fv/Fm.. 


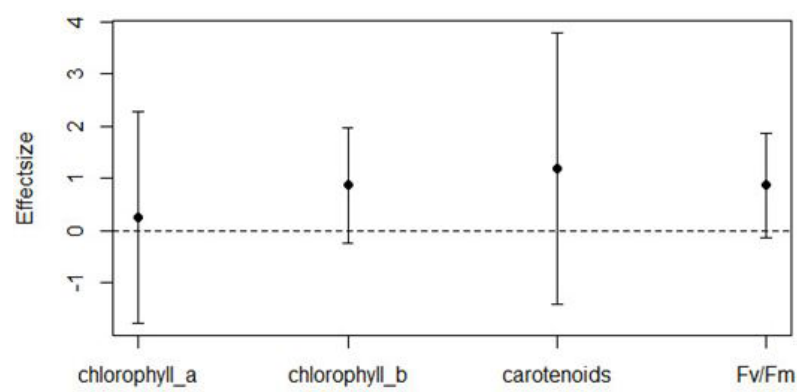

FIGURE 2 Effect size of toxic metals on chlorophyll a, chlorophyll b, carotenoids and Fv/Fm of Fabaceae species.

\section{DISCUSSION}

In this meta-analysis, we showed that toxic metals $(\mathrm{Pb}$ and $\mathrm{Al}$ ) affect plant physiology by reducing photosynthetic activity. Although photosynthesis is important to determine plant vigor, it is very vulnerable to stress by toxic metals (He et al., 20l8). Due to the toxicity of the metals, the photosynthetic apparatus is impaired, altering stomatal conduction, transpiration rate and the gas exchange associated with internal carbon. This may also influence the amount of plastid pigments, thus compromising photosynthesis (Fu and Wang, 20I5). Metals prevent chlorophyll $b$ from donating electrons to chlorophyllabydisrupting theacyclic photophosphorylation process that, consequently, prevents the absorption of light by damaging photosynthesis (Fu and Wang, 20I5; He et al., 2018).

Chlorophyll $\mathrm{a}$ is the main pigment responsible for capturing light. When toxic metals substitute elements of its chain it restricts the capacity to capture energy and the possibility of producing organic matter. Chlorophyll $b$ is also reduced when the plant is exposed to toxic metals, since the metals damage the thylakoid membranes and substitute compounds of the chlorophyll metabolic pathway (Fu and Wang 2015; Marques et al. 2018). Toxic metals may interfere with chlorophyll biosynthesis by inhibiting the formation of $\alpha$-aminolevulinic acid (ALA), as well as protochlorophyllide reductase, the key enzyme of phototransformation. However, the stabilization of carotenoid content in plants is generally related to increased tolerance to oxidative stress by toxic metals (Leal-Alvarado et al., 2016).

$\mathrm{Pb}$ negatively affected photosynthesis and $\mathrm{Fv} /$ $\mathrm{Fm}$. Although a higher proportion of $\mathrm{Pb}$ remains in the roots, this metal can directly or indirectly cause damage to shoots, mainly by affecting the performance of the photosynthetic apparatus (Leal-Alvarado et al., 2016, He et al., 2018). Pb inhibits the entire process of photosynthesis by reducing the photosynthetic rate, since it affects both photochemical and carboxylation reactions, causing changes in the organization of the chloroplast, modifying antioxidant enzymes that have the function of protecting plants, and changing photochemical reactions and carbon chains (He et al., 20I8).

When plants are exposed to $\mathrm{Pb}$, the photosynthetic rate is reduced because the chloroplast organization breaks, inhibiting the synthesis of plastoquinone and chlorophyll. This toxic metal also reduces chlorophyll content by inhibiting the synthesis and activity of enzymes. The substitution of central magnesium in the chlorophyll molecule by $\mathrm{Pb}$ is another explanation for the decline in the plastid pigment content. Lead can also prevent the capture of photosynthetic light in chlorophyll molecules affected by the substitution of metallic ions (He et al., 20I8).

The reduction of chlorophyll $\mathrm{b}$ by $\mathrm{Pb}$ is $\mathrm{a}$ defense mechanism in order to preserve the content of chlorophyll a, which is the most abundant pigment and plays a fundamental role in photosynthesis. It is known that $\mathrm{Pb}$ causes chlorosis and foliar atrophy, decreasing light absorption. Thus, the plant compensates for this damage using chlorophyll $b$ as an electron donor for chlorophyll a, which explains the reduction in chlorophyll b since this pigment is not replaced. However, chlorophyll b is a pigment that assists in the uptake of light and is an accessory pigment with a photoprotective effect; it reduces the harmful effects of light in the photosynthetic apparatus, avoiding damage to photosynthetic membranes (He et al., 2018; Marques et al., 2018). The $\mathrm{Fv} / \mathrm{Fm}$ decline reflects the structural damage to photosystem II and an increase in the dissipation of nonphotochemical energy as heat. Thus, the reduction of the quantum efficiency of photosystem II could be explained as a diminished ability of the plants to assimilate $\mathrm{CO} 2$ or as a result of oxidative phosphorylation (He et al., 20I8). In addition to the above facts, $\mathrm{Pb}$ is also responsible for oxidation that causes damage to the photosystem II reaction centers when they are overexcited. In photosystem II, loss of the DI protein involved in electron transfer between the reaction center of photosystem II and plastoquinone occurs (He et al., 2018).

Aluminum, when absorbed and accumulated in different parts of the plant, affects cells and their organelles at morphological, cytogenetic and physiological levels, impairing the functioning of the photosynthetic system and degrading the plastid pigments. Aluminum may also reduce the photochemical activity of the chloroplast, resulting in a decrease in the effective absorption of light energy and photosynthetic efficiency, and consequently changes the levels of chloroplast pigments (Rampim and 
Lana, 2013). Aluminum also causes oxidative damage by inhibiting aminolaevulinic acid, which plays an important role in the synthesis of chlorophyll (Mendes et al., 2018).

High concentrations of $\mathrm{Al}$ are detrimental to chlorophyll synthesis and result in the degradation of chlorophyll. Reduction in fresh and dry weights are directly linked to the reduction in the synthesis of plastid pigments due to the impediment of energy allocation between vegetative organs (Quian et al., 2018). Aluminum causes oxidation in the reaction centers and this process is irreversible and directly involves the light-receiving pigments, which are very excited and interact with $\mathrm{O}_{2}$ producing free radicals, such as superoxide $\left(\mathrm{O}_{2}-\right)$, which can destroy plastid pigments (Rampim and Lana, 2013).

The abundance of chlorophyll a associated with the high mobility of $\mathrm{Al}$ in the plant causes the replacement of magnesium (Mg) in the chain of chlorophyll by Al. This reduces the light absorbing capacity and, consequently, the photosynthetic capacity, and explains why the content of the pigment is reduced by the metal. The substitution of $\mathrm{Mg}$ by $\mathrm{Al}$ results in the blockade of normal activity and promotes changes in how the Calvin cycle functions, inhibiting photosynthetic electron transport (Rampim and Lana, 2013; Quian et al., 20l8).

Aluminum causes oxidation in carotenoid molecules, which have unsaturated and conjugated structures, resulting in complex products of their degradation. The intense oxidation results in the breakdown of the pigment, discoloration and loss of biological activity (Rampim and Lana, 20I3).

One of the largest botanical families is Fabaceae, which has a wide geographical distribution and is the third largest family of terrestrial plants in number of species. It is the second largest economically important family of angiosperms and includes many plants of food importance. Also, it has many taxa of great ornamental potential, is commonly planted in urban areas and, for this reason, suffers from contamination by toxic metals (Marques et al., 20l8). Pereira et al. (20l2), when studying the use of this family in the reforestation of contaminated areas, concluded that metals in the soil were at concentrations above the safe values established by legislation and that the plants established in the contaminated site were tolerant.

Even the metals did not interfere in the parameters analyzed in this family, the simple presence of lead or aluminum could reduce the maximum quantum efficiency of photosystem II due to the loss of complex proteins, closed reaction centers and the lack of the ability to transfer electrons, which reduces photochemical quenching. The presence of toxic metals reduces the absorption of light, which consequently reduces the excitation of the reaction centers. As a consequence, the plants absorb more water to perform photolysis, compensating for the loss of electrons. The metals also damage the cytochrome b6f complex, which is responsible for the connection between the photosystems, thus reducing the amount of $\mathrm{H}+$ protons and consequently reducing the formation of ATP (Elkhouni et al., 20l8).

\section{CONCLUSION}

Our meta-analysis revealed that the toxic metals have negative effects on plant physiology, when considering photosynthesis and the plastid pigments. However, each toxic metal ( $\mathrm{Pb}$ and $\mathrm{Al}$ ) has different effects when analyzed separately. $\mathrm{Pb}$, besides reducing chlorophyll b, also impairs photosynthesis and the maximum quantum efficiency of photosystem II, while aluminum is more harmful to plastid pigments. For Fabaceae species stressed by toxic metals, there is no change in the photosynthetic, plastid pigment content and the maximum quantum efficiency of photosystem II. The possible negative effects that toxic metals cause to the photosynthetic apparatus of plants are already known and there are few results in the literature that describe a beneficial effect of exposure to these metals. However, it was possible to verify through the cases that depending on the metal and parameter evaluated there can be no toxic effect or damage to the plant.

\section{ACKNOWLEDGMENTS}

The authors thank the following funding agencies: The Fundação de Amparo a Pesquisa do Estado de Minas Gerais (FAPEMIG) for the PIBIC / FAPEMIG scientific initiation scholarship awarded to TBW; the Coordination for the Improvement of Higher Education Personnel (CAPES) for the master's scholarship awarded to ARCN and fellowship PET SB; and the National Council of Scientific and Technological Development (CNPq) for the research grant awarded to SB.

\section{REFERENCES}

ELKHOUNI, A.; RABHI, M.; IVANOV, A.G.; KROL, M.; ZORRIG, W.; SMAOUI, A.; ABDELLY, C.; HUNER, N.P.A. Structural and functional integrity of Sulla carnosa photosynthetic apparatus under iron deficiency conditions. Plant Biology, v. 20, n. 3, p. 4I5-425, 2018.

FU, W.G.; WANG, F.K. Effects of high soil lead concentration on photosynthetic gas exchange and chlorophyll fluorescence in Brassica chinensis L. Plant, Soil and Environment, v. 6I, n. 7, p. 316-32I, 2015.

GUREVITCH, J.; KORICHEVA, J.; NAKAGAWA, S.; STEWART, G. Meta-analysis and the science of research synthesis. Nature, v. 555, n. 7695, p. 175-182, 2018. 
HE, B.; GU, M.; WANG, X.; HE, X. The effects of lead on photosynthetic performance of waxberry seedlings (Myrica rubra). Photosynthetica, v. 56, n. 4, p. II47-II53, 2018.

LEAL - ALVARDO, D.A.; ESPADAS - GIL, F; SÁENZ CARBONELL, L.; TALAVERA - MAY, C.; SANTAMARÍA, J.M. Lead accumulation reduces photosynthesis in the lead hyper-accumulator Salvinia minima Baker by affecting the cell membrane and inducing stomatal closure. Aquatic Toxicology, v. I7I, p. 37-47, 2016.

LI, Y.; DU, W.; ZHANG, Z.; ZHANG, L.; CHEN, Z.; HOU, W.; XU, S.; JIANG, L.; YU, N. Effects of complex pollution of $\mathrm{Pb}$ and $\mathrm{B}[\mathrm{a}] \mathrm{P}$ on the growth and physiological and biochemical indexes of ryegrass. Bulletin of Environmental Contamination and Toxicology, v. I01, n. I, p. 86-91, 2018.

MARQUES, D.M.; SILVA, A.B.; MANTOVANI, J.R.; PEREIRA, D.S.; SOUZA, T.C. Growth and physiological responses of tree species (Hymenaea courbaril L., Peltophorum dubium (Spreng.) Taub. and Myroxylon peruiferum L. F.) exposed to different copper concentrations in the soil. Revista Árvore, v. 42, n. 2, p. I-II, 2018.

MATSUMOTO, H.; MOTODA, $\mathrm{H}$. Oxidative stress is associated with aluminum toxicity recovery in apex of pea root. Plant and Soil, n. I-2, v. 363, p. 399-4I0, 2013.

MENDES, T.P.; OLIVEIRA, F.L.; TOMAZ, M.A.; RODRIGUES, W.N.; TEIXEIRA, A.G. Aluminum toxicity effect on the initial growth of yacon plantlets. Revista Ceres, v. 65, n. 2, p. $120-126,2018$.
OZYIGIT, I.I.; DOGAN, I.; IGDELIOGLU, S.; FILIZ, E.; KARADENIZ, S.; UZUNOVA, Z. Screening of damage induced by lead $(\mathrm{Pb})$ in rye (Secale cereale $\mathrm{L}$.) - a genetic and physiological approach. Biotechnology \& Biotechnological Equipment, v. 30, n. 3, p. I-8, 2016

PEREIRA, A.C.C.; RODRIGUES, A.C.D.; SANTOS, F.S.; GUEDES, J.N.; SOBRINHO, N.M.B.A. Concentração de metais pesados em espécies arbóreas utilizadas para revegetação de área contaminada. Revista Ciência Agronômica, v. 43, n. 4, p. 64I-647, 2012.

QUIAN, L.; HUANG, P.; HU, Q.; QUIAN, Y.; XU, S.; WANG, R. Morpho-physiological responses of an aluminumstressed rice variety 'liangyoupei 9'. Pakistan Journal of Botany, v. 50, n. 3, p. 893-899, 2018.

RAMPIM, L.; LANA, M.C. Mecanismo de tolerância interna das plantas ao alumínio. Colloquium Agrariae, v. 9, n. 2, p. 72-89, 2013.

TOZSÉR, D.; MAGURA, T.; SIMON, E. Toxic metal uptake by plant parts of willow species: A meta-analysis. Journal of Hazardous Materials, v. 336, p. I0I-109, 2017.

ZHANG, Y.H.; WANG, E.M.; ZHAO, T.F.; WANG, Q.Q.; CHEN, L.J. Characteristics of Chlorophyll Fluorescence and Antioxidant-Oxidant Balance in PEPC and PPDK Transgenic Rice under Aluminum Stress. Russian Journal of Plant Physiology, v. 65, n. I, p. 49-56, 2018. 